(Die Preisträgervorträge wurden in der Plenarsitzung am 16. November 2012 vorgetragen)

Der Dannie-Heinemann-Preis 2011/Award 2012 wurde Herrn Krzysztof Matyjaszewski, Pittsburgh/USA, für seine bahnbrechenden Arbeiten zu kontrollierten Polymerisationen, speziell für die Entwicklung der vielseitig zur Synthese strukturtreuer makromolekularer Verbindungen mit genau definierter Größe und Funktionnalität einsetzbaren ATRP-(Atom-Transfer Radical Polymerization)-Methodik verliehen.

\title{
Macromolecular Engineering by Tempering Radicals Behavior
}

\section{KRZYSZTOF MATYJASZEWSKI}

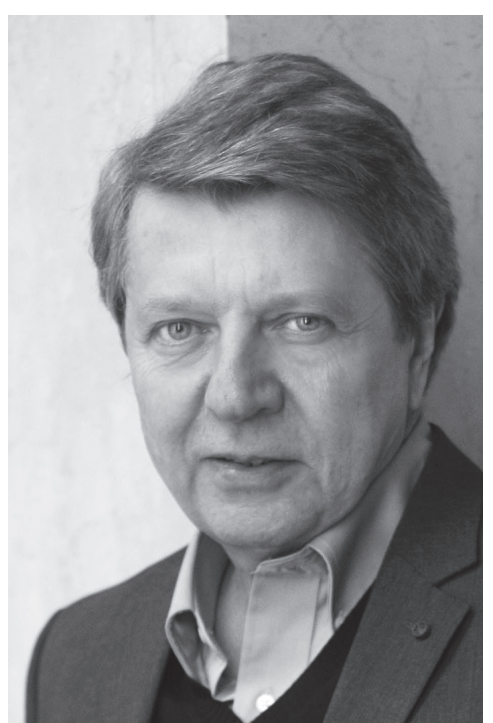

Krzysztof Matyjaszewski, Center for Macromolecular Engineering, Carnegie Mellon University, Pittsburgh, USA, Dannie-Heineman-Preisträger 2011
Currently over two hundred million metric tons of polymers are produced annually, i.e., one pound polymer per capita worldwide every week and thousands of publications containing the word polymer in their title are published each year. Indeed, polymers are preferred materials in applications for industrial practice and we all use them everyday. Polymers helped and enabled economic expansion and industrial revolution throughout the twentieth and beginning of twenty first century. Many modern day technologies emerged due to polymer science and its rapid progress. Aircraft and space industries, movies and music with its superabundance of vinyl records, CDs and DVDs, sport and outdoor equipment, and modern packaging are only a fraction of examples of polymeric materials being used today. Adhesives, sealants, coatings and paints are made from polymers. We now can't imagine life without polymer photoresists that enable microlithography to produce all the miniature electric circuits in our laptops, Iphones, Ipods, Ipads, or Blackberries. Interior of every automobile is essentially entirely made 
from polymers, but they are also used for body parts and for under-thehood applications. One could continue to cite and wonder over all of practical polymer achievements but one needs to realize that introduction many new applications requires synthesis of very precisely tailored polymers. The prerequisite for development of polymers for new advanced applications is very strict control of every detail of the molecular structure and chain architecture. Polymers produced in a such a precise way can organize at various scales ranging from millimetres down to nanometers and enable creation of new polymeric materials for areas of today's concerns, such as energy, environment or biomedicine. ${ }^{1,2}$

Nowadays, nearly half of all polymers are produced by conventional radical polymerization. However, they are predominantly used as commodity materials (polyethylene, polystyrene or poly (vinyl chloride)). Control over molecular structure in these systems is essentially impossible because radicals are very reactive intermediates and their lifetime is less than a second. ${ }^{3}$ During such a short time it is impossible to execute control over molecular structure. In order to temper this uncontrolled radical behavior, we introduced a new concept of extending life of propagating chains from ca. 1 second to more than 1 day, by inserting a dormant period of $\sim 1$ minute after each $\sim 1 \mathrm{~ms}$ activity. ${ }^{4}$ Thus, the $1 \mathrm{~s}$ of radical activity is expanded, as in an accordion, to several hours with thousands intermediate dormancy periods. This would be like extending human life from 70 years to 2000 years, if after each 1 day of activity we could be dormant for 1 month. This extension of the lifetime of growing chains from $1 \mathrm{~s}$ to over $1 \mathrm{~h}$ enabled synthesis of well-defined and essentially tailor-made polymers via macromolecular engineering.

Macromolecular engineering comprises precise design, synthesis, processing and characterization of targeted materials for specific applications. Many advanced nanostructured functional materials were recently designed and prepared by controlled/ radical polymerization (CRP) by tempering radical behavior and extending their lifetime by intermittent activation.

In 1995, we developed atom transfer radical polymerization (ATRP) one of the most powerful and robust CRP techniques. ${ }^{5}$ In ATRP the radical is intermittently masked as a dormant species. The initiator or a dormant species, an alkyl halide, is activated by a low-oxidation state transition metal (typically $\mathrm{Cu}^{\mathrm{I}}$ complexed by $\mathrm{N}$-based ligand), to form a propagating radical. The radical is quickly (after a few ms) deactivated by a higher-oxidation state transition metal (X-Cu ${ }^{\mathrm{II}}$ complex) and the dormant chain is re-generated. Equilibrium between dormant and growing species is strongly shifted to the side of dormant species. ${ }^{6}$ 
To make ATRP industrially acceptable and reduce its environmental impact, more efficient and 'greener' catalyst systems were developed. New ATRP techniques allow use of strongly diminished amounts of $\mathrm{Cu}$-based catalysts (a few parts per million) in the presence of environmentally friendly reducing agents such as ascorbic acid, sugars, zero valent metals such as $\mathrm{Cu}$ or $\mathrm{Fe}$, sulfites but also electrical current and light. For some applications, the removal of the tiny amounts of catalyst may be now unnecessary. It must be stressed that appropriate control of ATRP requires detailed knowledge of all relevant kinetic and thermodynamic parameters. ${ }^{7-10}$ Top part of Scheme 1 presents ATRP in the presence of reducing agents. ${ }^{11-13}$

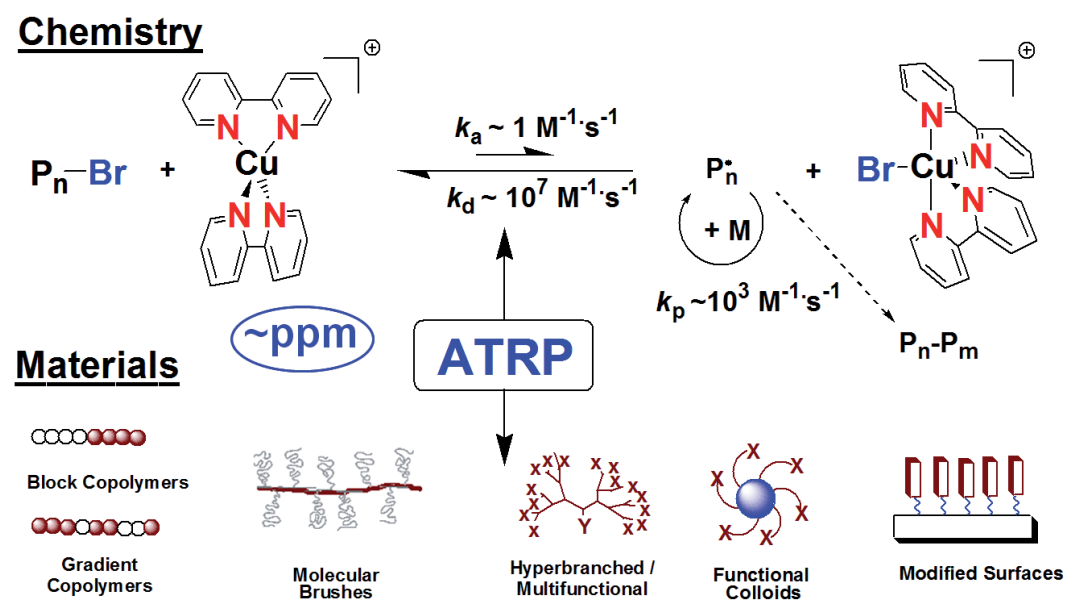

Scheme 1: Examples of Chemistry and Materials Prepared by ATRP

The bottom part of Scheme 1 illustrates some polymeric materials prepared by ATRP. They include block and gradient copolymers, molecular brushes, hyperbranched and multifunctional polymers, functional colloids and also modified surfaces. ${ }^{14}$

The precisely controlled polymers made by ATRP can self-assemble or be pre-assembled into various nanostructured morphologies but they can also form individual nano-objects. Scheme 2 shows some examples of such structures. They include (from left to right): organic colloidal particles with diameter $\mathrm{d}=50 \mathrm{~nm}$ decorated with hairy grafts, nanostructured carbon filaments $(\mathrm{d}=30 \mathrm{~nm})$ prepared from polyacrylonitrile, molecular bottlebrushes with $150 \mathrm{~nm}$ length, silica particles $(\mathrm{d}=20 \mathrm{~nm})$ with long stabilizing poly(n-butyl acrylate) side chains and poly methacrylate backbone, and organic-inorganic hybrid materials consisting of silica nanoparticles with 

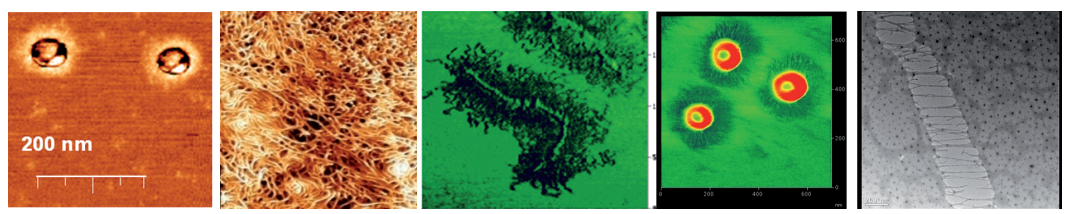

Scheme 2: Examples of Nanostructured Materials by ATRP

polystyrene chains that strongly enhance mechanical properties by toughening and exhibiting crazing phenomena.

Most recent developments include materials for drug and nucleic acid delivery, smart, intelligent materials that respond to various external stimuli that can exhibit shape memory and self-healing properties, materials for reversible $\mathrm{CO}^{2}$ capture, oxygen reduction, energy storage and many others.

The polymers prepared by ATRP are now commercially produced in USA, Japan and Europe ${ }^{15}$ as components of various advanced materials such as health and beauty products, biomedical and electronic materials, coatings, elastomers, adhesives, surfactants, dispersants, lubricants, additives, or sealants.

Acknowledgments. Creative contributions and discussions with many collaborators and over 100 postdoctoral fellows and graduate students at Carnegie Mellon University are gratefully acknowledged.

\section{References:}

(1) Matyjaszewski, K.; Moeller, M., Eds. Polymer Science: A Comprehensive Reference; Elsevier BV: Amsterdam, 2012.

(2) Matyjaszewski, K.; Gnanou, Y.; Leibler, L. Macromolecular Engineering. Precise Synthesis, Materials Properties, Applications; Wiley-VCH: Weinheim, 2007.

(3) Matyjaszewski, K.; Davis, T.P. Handbook of Radical Polymerization; Wiley-Interscience: Hoboken, 2002.

(4) Matyjaszewski, K., Atom Transfer Radical Polymerization (ATRP): Current Status and Future Perspectives, Macromolecules (Washington, DC, U.S.) 2012, 45, 40154039.

(5) Wang, J.-S.; Matyjaszewski, K., Controlled/ „living“ radical polymerization. atom transfer radical polymerization in the presence of transition-metal complexes, J. Am. Chem. Soc. 1995, 117, 5614-5615.

(6) Matyjaszewski, K.; Xia, J., Atom Transfer Radical Polymerization, Chem. Rev. 2001, 101, 2921-2990.

(7) Wang, Y.; Kwak, Y.; Buback, J.; Buback, M.; Matyjaszewski, K., Determination of ATRP Equilibrium Constants under Polymerization Conditions, ACS Macro Letters 2012, 1, 1367-1370. 
(8) Morick, J.; Buback, M.; Matyjaszewski, K., Effect of Pressure on Activation-Deactivation Equilibrium Constants for ATRP of Methyl Methacrylate, Macromol. Chem. Phys. 2012, 213, 2287-2292.

(9) Soerensen, N.; Barth, J.; Buback, M.; Morick, J.; Schroeder, H.; Matyjaszewski, K., SP-PLP-EPR Measurement of ATRP Deactivation Rate, Macromolecules (Washington, DC, U. S.) 2012, 45, 3797-3801.

(10) Morick, J.; Buback, M.; Matyjaszewski, K., Activation-Deactivation Equilibrium of Atom Transfer Radical Polymerization of Styrene up to High Pressure, Macromol. Chem. Phys. 2011, 212, 2423-2428.

(11) Tsarevsky, N.V.; Matyjaszewski, K., „Green“ Atom Transfer Radical Polymerization: From Process Design to Preparation of Well-Defined Environmentally Friendly Polymeric Materials, Chemical Reviews (Washington, DC, United States) 2007, 107, 2270-2299.

(12) Magenau, A.J.D.; Strandwitz, N. C.; Gennaro, A.; Matyjaszewski, K., Electrochemically Mediated Atom Transfer Radical Polymerization, SCIENCE 2011, 332, 8184.

(13) Konkolewicz, D.; Schroder, K.; Buback, J.; Bernhard, S.; Matyjaszewski, K., Visible Light and Sunlight Photoinduced ATRP with ppm of Cu Catalyst, ACS Macro Letters 2012, 1, 1219-1223.

(14) Matyjaszewski, K., Architecturally complex polymers with controlled heterogeneity, Science (Washington, DC, United States) 2011, 333, 1104-1105.

(15) Matyjaszewski, K.; Spanswick, J., Controlled/living radical polymerization, Materials Today (Oxford, United Kingdom) 2005, 8, 26-33. 